\title{
Evidence for glutamate as the neurotransmitter of corticothalamic and corticorubral pathways
}

MARK B. BROMBERG, JOHN B. PENNEY, JR., BARBARA S. STEPHENSON and ANNE B. YOUNG

University of Michigan, Department of Neurology, Neuroscience Laboratory, 1103 E. Huron St., Ann Arbor, Mich. 48109 (U.S.A.)

(Accepted February 12th, 1981)

Key words: glutamate - neurotransmitter — corticothalamic pathway - corticorubral pathway

Despite extensive investigations of the anatomy and physiology of descending pathways from the cortex, little is known of the neurotransmitter(s) mediating cortical activity. Extracellular and intracellular recordings after iontophoretic application of glutamate and acetylcholine suggest that glutamate has selective excitatory actions on rubral and thalamic neurons while acetylcholine has little effect in red nucleus ${ }^{1-3}$. Furthermore, biochemical studies have related glutamate to cortical fiber terminals by showing that in rat there is a decrease in high affinity glutamate uptake into homogenates of thalamus after hemidecortication ${ }^{8}$. High affinity glutamate uptake into brain slices or synaptosomes has been used as one of the most reliable markers for glutamatergic terminals $\mathbf{s}^{\mathbf{8}, 25}$. We have undertaken an initial study to clarify and further characterize the neurotransmitter of the corticothalamic and corticorubral pathways in the rat by measuring changes in high affinity glutamate uptake and changes in amino acid concentration in deafferented thalamic and rubral tissue following sensorimotor cortical ablations. We report evidence favoring glutamate as the transmitter mediating excitatory cortical activity at these nuclei.

Adult male Sprague-Dawley rats received either a bilateral sensorimotor cortical ablation ${ }^{22}$, a unilateral sensorimotor ablation, or a sham operation involving craniotomy but no cortical destruction. Cortical ablations were made by removing the skull and aspirating the cortex down to white matter and by undercutting the cortex with a curved needle for 3-5 mm along the lateral edge of the aspiration site. After 2-3 week survival periods, the animals were decapitated, their brains immediately removed, photographed and placed in $4{ }^{\circ} \mathrm{C}, 0.32 \mathrm{M}$ buffered sucrose solution. At $4{ }^{\circ} \mathrm{C}$ the brains were cut in the coronal plane into $1 \mathrm{~mm}$ thick slices containing the cortical lesion site, the ventral thalamic nuclei and red nuclei. Under a dissecting microscope, tissue samples were obtained by pressing glass capillary tubing $(1 \mathrm{~mm}$ i.d.) through the ventroanterolateral thalamic nuclei ${ }^{6}$ and the anteroventral part of the red nuclei ${ }^{12}$. The 
tissue cores $(1.0-3.0 \mathrm{mg})$ were placed either in tubes containing $1 \mathrm{ml}$ cold buffered sucrose solution or on foil and then frozen over dry ice and stored at $-70{ }^{\circ} \mathrm{C}$.

The tissue was homogenized in $1 \mathrm{ml}$ cold $0.32 \mathrm{M}$ buffered sucrose solution in a Tefion-glass homogenizer, diluted 5-fold with cold sucrose, and spun at 20,000 $\times g$ for $20 \mathrm{~min}$. The resultant supernatant was discarded and the combined $P_{1}-P_{2}$ pellet was resuspended in cold $0.32 \mathrm{M}$ buffered sucrose. High affinity uptake was measured with $\mathrm{L}-\left[{ }^{3} \mathrm{H}\right]$ glutamate $\left(27 \mathrm{Ci} / \mathrm{mmol}\right.$, Amersham) at $10^{-8} \mathrm{M}$ as previously described ${ }^{25}$, and the radioactivity determined by liquid scintillation spectrometry (Beckman LS 8100 , efficiency $38 \%$ ). Amino acid levels were determined by high pressure liquid chromatographic (HPLC) separation of their ortho-phthaldialdehyde (OPA) derivatives by a modification of previous techniques ${ }^{10,11,14}$. Analyses were performed at room temperature with a Brownlee Spheri-5A $\left(5 \mu \mathrm{m}, \mathrm{C}_{18}\right)$ reverse phase column using a $0.1 \mathrm{M}$ sodium acetate (Baker) aqueous eluent (A) pH 5.5, and methanol as an organic modifier (B) (HPLC grade, Baker). The sample ran isocratically at $35 \%$ B in A for 6 min followed by a gradient to $70 \% \mathrm{~B}$ over $8 \mathrm{~min}$. Proteins were measured by the method of Lowry et al. ${ }^{15}$.

Measurement of high affinity glutamate uptake required the combined tissue of both thalamic nuclei or both red nuclei in order to make reliable determinations. Consequently, for these studies, the experimental animals received bilateral cortical lesions and were compared to age- and sex-matched control animals. Other studies required less tissue and unilateral lesions were made with the contralateral side serving as a control.

Two rats received a unilateral cortical ablation and after 5 days their brains were perfused, sectioned and stained for degenerating fibers and axon terminals by the Fink-Heimer method 7 . Confirmation that the punch sites were within the cortical fiber terminal distribution areas in thalamus and red nucleus and that the ablation destroyed pyramidal-corticospinal neurons was obtained by determining the location of degenerating terminals in these animals. Extensive degeneration in the ipsilateral anteroventrolateral, ventral basal, and ventral medial nuclei of the thalamus (Fig. 1c) and moderate degeneration in the ventroanterior part of the ipsilateral red nucleus (Fig. If) was found and degenerating terminals were seen along the entire course of the corticospinal tract.

Slices containing the ablation and punch sites from the animals used in the biochemical studies were cut serially into $25 \mu \mathrm{m}$ frozen sections and stained for verification of placement. Animals excluded from statistical analysis were those in which the lesion was not confined to the sensorimotor cortex ${ }^{22}$, or where the punches were not within the anteroventrolateral nucleus of the thalamus ${ }^{6}$, or ventroanterior part of the red nucleus ${ }^{12}$. Thalamic punches were included if they contained up to $30 \%$ tissue of the ventral basal or ventral medial nuclei and rubral punches were included if they contained up to $30 \%$ medial lemniscus tissue.

The concentrations of a number of anino acids were measured in thalamic tissue from unilaterally decorticate animals by HPLC (Fig. 2, upper histogram). Glutamate levels were reduced by $26 \%$ compared to the control side $(P<0.002)$. There were no significant changes in other amino acids. Amino acid levels were also measured in 




Fig. 1. Location of tissue punch sites and degeneration pattern following unilateral sensorimotor cortical ablation. a, b, c: cross-sections through the thalamus showing the absence of degeneration contralateral to the cortical ablation (a), the distribution of degeneration (hatched areas) and the punch sites (black circles) (b), and the fine black granules in Fink-Heimer staining which represent the degenerating terminals ipsilateral to ablation (c). $d, e, f$ : cross-sections through red nucleus showing lack of degenerating fibers contralateral to ablation (d), the distribution of degeneration and punch sites (e), and degenerating terminals ipsilateral to ablation (f). (Magnification of Fink-Heimer stained sections: $500 \times$.)

rubral tissue but no significant changes in glutamate or other amino acids related to the deafferentation were detected.

The high affinity uptake of glutamate in ventrolateral thalamic tissue was reduced by $48 \%$ and the uptake in rubral tissue reduced by $67 \%$ following cortical ablations as compared to control animals (Fig. 2, lower histogram). Dose-response studies of the changes in high affinity glutamate uptake were carried out in thalamic tissue. Analysis of double-reciprocal plots of the data (Fig. 3) shows a decrease in $\mathrm{V}_{\max }$ of the uptake system $(7.1 \mathrm{nmol} / 5 \mathrm{~min} / \mathrm{mg}$ protein in the experimental animals compared to $10.6 \mathrm{nmol} / 5 \mathrm{~min} / \mathrm{mg}$ protein in the control animals) without a significant change in $K_{m}(4.4 \mu \mathrm{M}$ in experimental animals compared to $4.8 \mu \mathrm{M}$ in control animals). Thus, the decrease in high affinity glutamate uptake reflects a reduction in the number of binding sites with little change in the affinity of the transport system for its substrate.

L-Glutamate is an acidic amino acid which depolarizes most central nervous system neurons, and recent evidence gives support for glutamate as a neurotransmitter $4,8,25$. High affinity uptake systems for amino acid neurotransmitter candidates have been demonstrated and their measurement found useful in estimating the density of presynaptic amino acidergic terminals in specific areas ${ }^{8,13,20}$. However, aspartate and glutamate share a common transport system and it is necessary to measure amino acid levels to differentiate the two acidic amino acids. Using these biochemical 

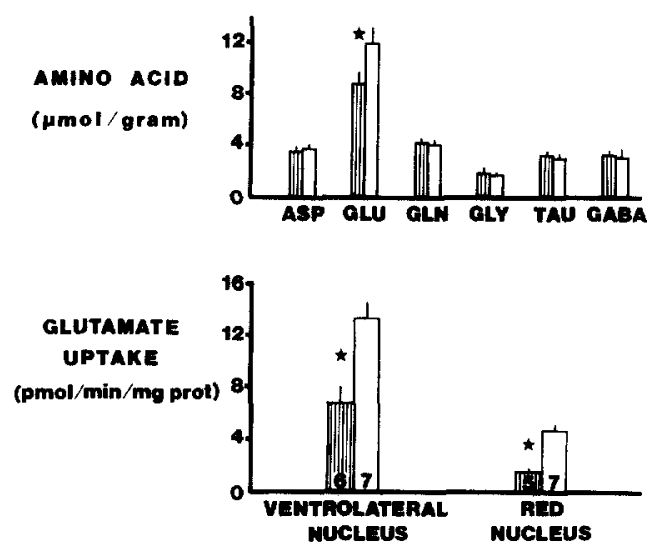

Fig. 2. Upper histogram: levels of amino acids in ventrolateral nucleus of thalamus ( $\mu \mathrm{mol} / \mathrm{g}$ wet weight of tissue \pm S.E.M.). The values represent the mean of determinations on 8 animals. Striped bars, thalamus ipsilateral to 2-week-old unilateral sensorimotor cortical ablation. Open bars, thalamus contralateral to cortical ablation. Lower histogram: $\mathrm{L}-\left[{ }^{3} \mathrm{H}\right] g l u t a m a t e ~ u p t a k e ~\left(10^{-8} \mathrm{M}\right)$ in homogenates of ventrolateral nucleus of thalamus and red nucleus ( $\mathrm{pmol} / \mathrm{min} / \mathrm{mg}$ protein \pm S.E.M.). Striped bars, tissue ipsilateral to 2-week-old unilateral sensorimotor cortical ablation. Open bars, tissue contralateral to cortical ablation. Numbers in bars refer to sample size. Stars in upper and lower histograms indicate significant differences at $P<0.005$ (paired $t$-test).

techniques and correlating the results with anatomical and physiologic data, several presumptive glutamatergic pathways have been demonstrated ${ }^{1,4,8,17-19,25}$.

In this study, a concomitant and significant reduction in glutamate levels (26\%) and in high affinity uptake $(48 \%)$ in ventrolateral nucleus was observed after sensorimotor cortical ablations. No changes in the levels of other putative amino acid neurotransmitters were seen. In red nucleus, there also was a significant reduction in high affinity glutamate uptake $(67 \%)$ in lesioned animals but no changes in glutamate or other amino acid levels were seen. The change in uptake in the thalamus reflects a change in the number of uptake sites and not in the affinity of the uptake system, which is as expected with a loss of glutamatergic terminals.

In control animals, the magnitude of glutamate uptake in ventrolateral thalamus is greater than in red nucleus. This probably reflects the larger size and higher density of presumed glutamatergic terminals (Fig. 1c, f). The per cent reduction in glutamate uptake is greater in red nucleus than in thalamus, indicating possibly, that the ventrolateral thalamus receives a greater proportion of glutamatergic inputs from sources other than the cerebral cortex. The failure to find a decrease in glutamate or aspartate levels in the red nucleus after cortical ablation suggests that the neurotransmitter pool of these amino acids is small in comparison to the other metabolic pools. In the case of glutamate the other pools are substantial ${ }^{25}$. Furthermore, in red nucleus, the tissue samples contained portions of surrounding tissue as well as the nucleus itself. It would be very difficult to ascertain small changes under these conditions.

The cortical tissue removed in these experiments includes electrically excitable sensorimotor cortex ${ }^{23}$ and the cells of origin of the corticospinal tract ${ }^{9}$. Many of the corticofugal fibers to the ventrolateral nuclei of the thalamus and red nucleus are 


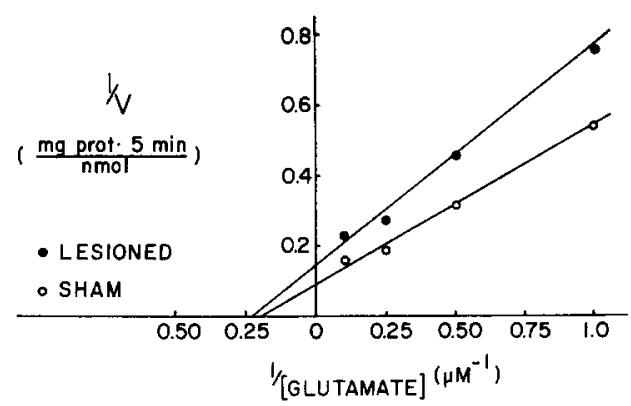

Fig. 3. Double reciprocal plot of uptake into homogenates of ventrolateral thalamus of decorticated rats and their sham-operated controls. Velocity (V) is expressed as nanomoles of glutamate accumulated $/ 5 \mathrm{~min} / \mathrm{mg}$ protein. The experimental values represent the mean of triplicate determinations and the experiment has been repeated 3 times.

collaterals of corticospinal fibers ${ }^{5}$. Recent physiologic data suggest that L-glutamate may be the neurotransmitter of corticofugal fibers ${ }^{17-19}$. Our biochemical data support further the hypothesis that glutamate is the likely neurotransmitter candidate for the corticospinal tract and recent biochemical data in cat support this hypothesis ${ }^{24}$. In studies of rats after cortical ablations or after spinal cord transection, we have found no changes in spinal cord glutamate levels or uptake. However, in rat the crosssectional area of the corticospinal tract at the lumbar level is only about $5 \%$ of the entire cord cross-section and the density of corticospinal endings in lumbar cord is very low ${ }^{9}$. Even if there were no other glutamatergic inputs to spinal cord (which is a poor assumption), it would be difficult to ascertain any changes after cortical ablations.

In summary we carried out biochemical studies to determine if an amino acid is the neurotransmitter of excitatory corticofugal fibers. We found a significant decrease in levels of L-glutamate but not of other amino acids in the ventrolateral thalamus of rats two weeks after ablation of sensorimotor cortex. The animals also show significant decreases in high affinity uptake of L-glutamate in ventrolateral thalamus and red nucleus. These results strengthen electrophysiological (iontophoretic) data that glutamate mediates cortically-evoked excitation at these sites.

The authors wish to thank Joseph Robertson and Frank Hospod for their assistance. This work was supported in part by United Cerebral Palsy Educational and Research Foundation Grants R-301-78 and R-305-79 and by UPSHS Grants NS00464-01, NS00420-01 and NS15140-02.

1 Altmann, H., ten Bruggencate, G., Picklemann, P. and Steinberg, R., Effects of glutamate, aspartate and two presumed antagonists on feline rubrospinal neurones, Pflüger's Arch., 364 (1976) 249-255.

2 Anderson, P. and Curtis, D. R., The excitation of thalamic neurones by acetylcholine, Acta. physiol. scand., 61 (1964) 85-99.

3 Davis, R. and Vaughan, P. C., Pharmacological properties of feline red nucleus, Int. J. Neuropharmacol., 8 (1969) 475-488. 
4 Divac, I, Fonnum, F. and Storm-Mathisen J., High affinity uptake of glutamate in terminals of corticostriatal axons, Nature (Lond.), 266 (1977) 377-378.

5 Endo, K., Araki, T. and Yagi, N., The distribution and pattern of axon branching of pyramidal tract cells, Brain Research, 57 (1973) 484-491.

6 Faull, R. L. M. and Mehler, W. R., Subdivision of the ventral tier nuclei in the red nucleus based on their afferent fiber connections, Anat. Rec., 184 (1976) 400.

7 Fink, R. P. and Heimer, L., Two methods for selective impregnation of degenerating axons and their synaptic endings in the central nervous system, Brain Research, 4 (1967) 369-374.

8 Fonnum, F., Comments on localization of neurotransmitters in the basal ganglia. In F. Fonnum (Ed.), Amino Acids as Neurotransmitters, Plenum, New York, 1978, pp. 143-153.

9 Hicks, S. P. and D'Amato, C. J., Motor-sensory cortex-corticospinal system and developing locomotion and placing in rats, Amer. J. Anat., 143 (1975) 1-42.

10 Hodgin, J. C., The separation of pre-column o-phthaldialdehyde derivatized amino acids by high performance liquid chromatography, J. Liquid Chromatogr. 2 (1979) 1047-1059.

11 Hospod, F. E. and Young, A. B., HPLC determination of neurotransmitter amino acids in brain and spinal cord, in preparation.

12 König, J. F. R. and Klippel, R. A., The Rat Brain: A Stereotaxic Atlas of the Forebrain and Lower Parts of the Brain Stem, Kreiger, Huntington, New York, 1963.

13 Kuhar, M. J., Neurotransmitter uptake: a tool in identifying neurotransmitter-specific pathways, Life Sci., 13 (1973) 1623-1634.

14 Lindroth, P. and Mopper, K., High performance liquid chromatographic determination of subpicomole amounts of amino acids by precolumn fluorescence derivatization with o-phthaldialdehyde, Analyt. Chem., 51 (1979) 1667-1674.

15 Lowry, O. H., Rosebrough, N. J., Farr, A. L. and Randall, R. J., Protein measurement with the Folin phenol reagent, J. biol. Chem., 193 (1951) 265-275.

16 Nakamura, Y., Mizuno, N., Konishi, A. and Sato, M., Synaptic reorganization of the red nucleus after chronic deafferentation from cerebellorubral fibers: an electron microscope study in the cat, Brain Research, 82 (1974) 298--301.

17 Stone, T. W., Cortical pyramidal tract interneurons and their sensitivity to L-glutamic acid, $J$. Physiol. (Lond.), 233 (1973) 211-225.

18 Stone, T. W., Blockade by amino acid antagonists of neuronal excitation mediated by the pyramidal tract, J. Physioi. (Lond.), 257 (1976) 187-198.

19 Stone, T. W., Amino acids as neurotransmitters of corticofugal neurones in the rat: a comparison of glutamate and aspartate, Brit. J. Pharmacol.67 (1979) 545-551.

20 Storm-Mathisen, J., Fonnum, F. and Malthe-Sorenssen, D., GABA uptake in nerve terminals. In E. Roberts, T. N. Chase and D. B. Tower, (Eds.), GABA in Nervous System Function, Raven Press, New York, 1976, pp. 387--394.

21 Tsukahara, N., Hultborn, H., Murakami, F. and Fujito, M., Electrophysiological study of the formation of new synapses and collateral sprouting in the red nucleus after partial denervation, $J$. Neurophysiol., 38 (1975) 1359-1372.

22 Webster, K. E., Cortico-striate interrelations in the albino rat, J. Anat. (Lond.) 95 (1961) 532-544.

23 Woolsey, C. N., Settlage, P. H., Meyer, D. R., Spencer, W., Hamuy, T. P. and Travis, A. M., Patterns of localization in precentral and "supplementary" motor areas and their relation to the concept of a premotor area, Res. Publ. Ass. nerv. ment. Dis., 30 (1952) 238-264.

24 Young, A. B., Bromberg, M. B. and Penney, J. B., Ablation of feline sensorimotor cortex decreases glutamate uptake in the projection areas of corticospinal tract, $J$. Neurosci, in press.

25 Young, A. B., Oster-Granite, M. L., Herndon, R. M. and Snyder, S. H., Glutamic acid: Selective depletion by viral induced granule cell loss in hamster cerebellum, Brain Research, 73 (1974) 1-13. 